\title{
Role of aromatase inhibitors in breast cancer
}

\author{
R Carpenter' and WR Miller,2 \\ 'The Breast \& Endocrine Unit, 2nd Floor West Wing, St Bartholomew's Hospital, London ECIA 7BE, UK; ${ }^{2}$ Edinburgh Breast Unit Research Group, \\ Western General Hospital, University of Edinburgh, Paderewski Building, Edinburgh EH4 2XU, UK
}

Primarily, the role of the aromatase inhibitors has been investigated in postmenopausal women with breast cancer, although it is also now being assessed in premenopausal patients following ovarian ablation/suppression. Aromatase inhibitors markedly suppress endogenous oestrogens without directly interacting with oestrogen receptors, and thus have a different mechanism of action to the antioestrogen, tamoxifen. The inhibitors may be divided into subgroups according to their structure (steroidal and nonsteroidal), and there appears to be a lack of cross-resistance between the classes of aromatase inhibitors enabling them to be used sequentially and potentially to prolong endocrine hormone therapy. In addition, with increased efficacy and favourable safety and tolerability profiles, the aromatase inhibitors are starting to challenge tamoxifen as first choice endocrine treatment in a number of settings. Potential differences in side-effect profiles may appear between the steroidal and nonsteroidal aromatase inhibitors when used in long-term settings. Thus, it has been suggested that the steroidal agents have favourable end organ effects; for example, the steroidal inhibitor, exemestane, has minimal negative effects on bone and lipid metabolism in animal and clinical studies. This paper provides an overview of the current and future roles of aromatase inhibitors for breast cancer treatment.

British Journal of Cancer (2005) 93 (SuppI I), SI -S5. doi:I0.1038/sj.bjc.6602688 www.bjcancer.com

(c) 2005 Cancer Research UK

Keywords: aromatase inhibitors; tamoxifen; breast cancer; future treatment

With many breast cancers requiring oestrogen for growth, hormone therapy has focused on suppressing the synthesis and action of these hormones. The gold standard for hormone therapy in premenopausal women has been ovarian ablation, with antioestrogens (such as tamoxifen) being primarily used in postmenopausal patients. However, in postmenopausal women, an alternative approach is to target the aromatase enzyme, which is responsible for the conversion of androgens to oestrogens and is the key step in oestrogen biosynthesis. Recent clinical trial results with aromatase inhibitors suggest this approach has an important role in treatment of $\mathrm{ER}$ and/or $\mathrm{PgR}$ positive breast cancers.

\section{RATIONALE FOR AROMATASE INHIBITORS IN BREAST CANCER}

Oestrogen deprivation has long been an effective treatment for breast cancer (Beatson, 1896), and the introduction of the antioestrogen, tamoxifen, in the 1970s produced marked improvements in breast cancer survival (EBCTCG, 1998). Tamoxifen blocks the oestrogen receptor, whose signalling represents a critical growth and survival pathway in breast tumours. However, tamoxifen also has some partial oestrogen agonist effects, which may be detrimental, and may be associated with increased risk of uterine cancer and thromboembolism. Agonist activity may also be involved in the development of tamoxifen resistance (Smith and Dowsett, 2003).

An alternative approach to blocking the oestrogen receptor is to reduce levels of its ligand, oestradiol, by targeting aromatase. This

\footnotetext{
*Correspondence: Professor WR Miller; E-mail: w.r.miller@ed.ac.uk
}

enzyme converts androstenedione and testosterone to oestrone and oestradiol (Gruber et al, 2002). It is a member of the cytochrome $P 450$ class and is highly expressed in the placenta and in the granulosa cells of ovarian follicles. However, it is also present in peripheral tissues, including adipose tissue, liver, muscle, brain and breast cancer tissue (Miller, 1991; Simpson and Davis, 2001).

Unlike tamoxifen, aromatase inhibitors do not directly interact with the oestrogen receptor but indirectly affect signalling in postmenopausal women by blocking the conversion of adrenal androgens to oestrogen in peripheral (ie non-ovarian) tissues, including the breast itself (Figure 1; Miller, 1991). Enhanced aromatase activity has been observed in adipose tissue adjacent to breast cancers (O'Neill et al, 1988), and may promote growth of malignant cells (O'Neill et al, 1988). Aromatase inhibitors inhibit in situ oestrogen synthesis in both tumour and non-malignant breast tissue (Miller and Dixon, 2001), and have demonstrated efficacy in suppressing peripheral oestrogen synthesis in postmenopausal women (Smith and Dowsett, 2003).

Aromatase inhibitors may be divided into two subtypes, steroidal and nonsteroidal. Steroidal inhibitors (eg exemestane) are analogues of androstenedione and bind irreversibly to the substrate binding site on the aromatase molecule, and are also known as enzyme inactivators. Nonsteroidal inhibitors (eg anastrozole and letrozole) bind reversibly to the haem group of the enzyme. The clinical significance of this difference in mechanism of action is uncertain at present, although it may enable the different types of agent to be used sequentially in order to prolong clinical response (Lønning et al, 2000; Bertelli et al, 2002). Later in the supplement, Dr Bertelli discusses sequencing of therapy further.

Several trials have shown that aromatase inhibitors are effective for the treatment of postmenopausal women who have experienced 
S2

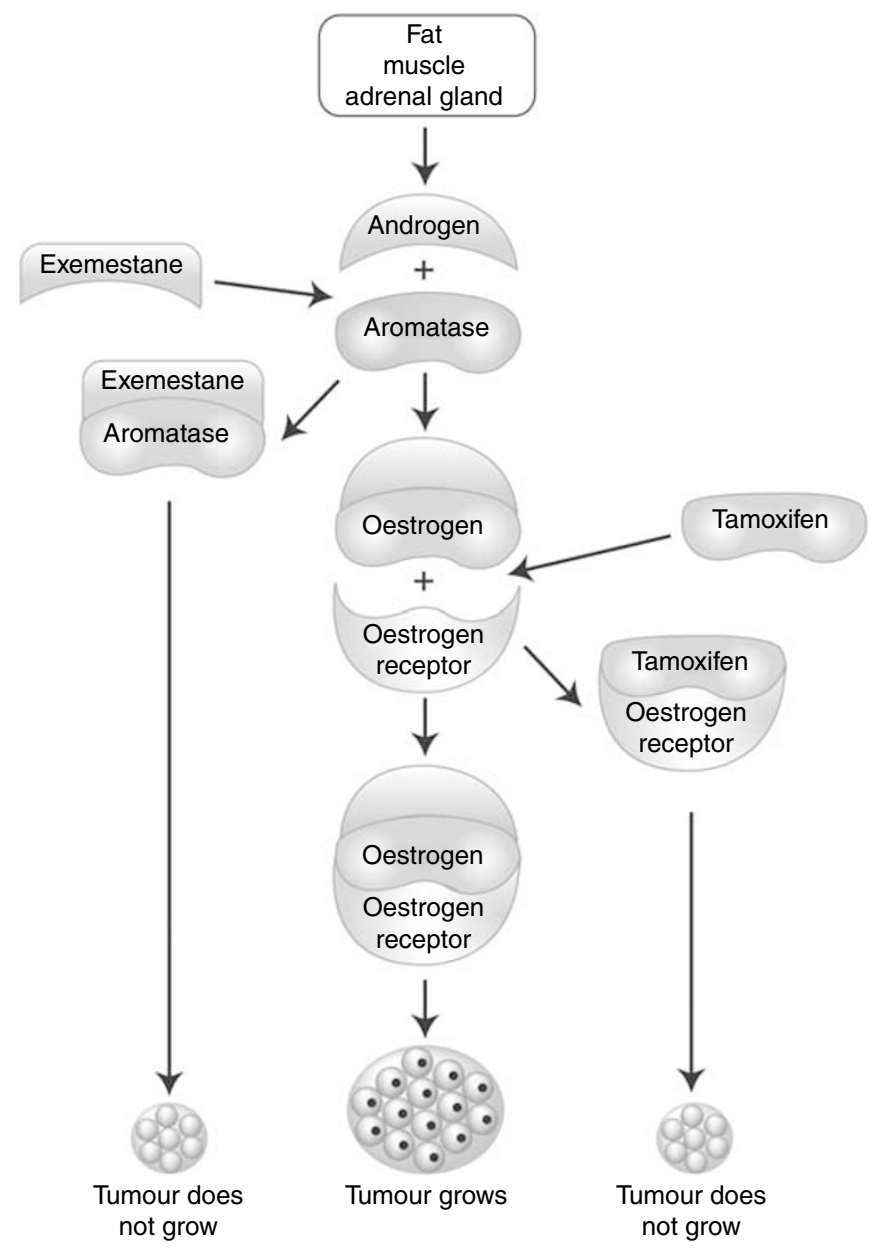

Figure I Mechanisms of action of tamoxifen and exemestane.

disease progression while on tamoxifen and in the first-line setting (Nabholtz et al, 2000; Milla-Santos et al, 2000; Dirix et al, 2001; Mouridsen et al, 2001). In the adjuvant and neoadjuvant settings:

- The Arimidex, Tamoxifen Alone or in Combination (ATAC) study (ATAC, 2002; Buzdar, 2004) has shown the aromatase inhibitor, anastrozole, to be more effective than tamoxifen in terms of disease-free survival (DFS) with several important tolerability benefits.

- The Intergroup Exemestane Study (IES) showed that switching to exemestane after only 2-3 years of tamoxifen therapy significantly improved DFS $v s$ the standard 5 years of tamoxifen therapy (Coombes et al, 2004).

- Results from the MA-17 trial indicated that following the completion of standard adjuvant tamoxifen therapy, letrozole treatment improved DFS compared with placebo (Goss et al, 2003).

- In the neoadjuvant setting, the P024 trial demonstrated that women with oestrogen receptor-positive primary breast cancer who received letrozole were more likely to receive breast conserving surgery compared with those treated with tamoxifen (Ellis et al, 2001).

\section{CURRENT GUIDELINES AND THE AROMATASE INHIBITORS}

Both the National Comprehensive Cancer Network (2005) and The Cancer Care Ontario Practice Guidelines Initiative (Breast Cancer
Disease Site Group, 2002) have added aromatase inhibitors to their guidelines alongside tamoxifen as first-line therapy in postmenopausal oestrogen receptor-positive women with advanced breast cancer. The European Society of Mastology has also added aromatase inhibitors as first-line therapy in their advanced breast cancer guidelines (Blamey, 2002).

Following the publication of the first results from the ATAC study (ATAC, 2002), the American Society of Clinical Oncology (ASCO) reviewed their guidelines on adjuvant treatment of breast cancer (Winer et al, 2002, 2003). Their recommendations were that a 5-year course of tamoxifen should remain as standard therapy with adjuvant therapy with an aromatase inhibitor only in postmenopausal women with a relative or absolute contraindication to tamoxifen.

\section{CURRENT PRACTICE}

In advanced disease, in the first-line setting, anastrozole, letrozole and exemestane have proved to be more clinically efficient than tamoxifen in prospective randomised trials and demonstrate a more favourable side-effect profile (Bonneterre et al, 2000; Nabholtz et al, 2000; Paridaens et al, 2000, 2003; Mouridsen et al, 2001; Howell et al, 2003). In previous studies, all three have also demonstrated superiority over megestrol acetate in the second-line setting after tamoxifen failure (Buzdar et al, 1996, 1997; Dombernowsky et al, 1998; Goss et al, 1999; Kaufmann et al, 2000). Exemestane and letrozole have been shown to be active and well tolerated after tamoxifen and megestrol acetate failure in the third-line setting (Ingle et al, 1997; Jones et al, 1999). Furthermore, an apparent lack of cross-resistance between the aromatase inhibitors offers the possibility of sequential use in advanced disease (see Dr Bertelli's article later in this supplement).

In the neoadjuvant setting, letrozole has proved to be superior to tamoxifen both in terms of tumour response and breast conservation rate (Eiermann et al, 2001). Interestingly, a biological evaluation of the study showed that tumours which overexpressed HER2 receptors were more likely to respond to the aromatase inhibitor than to tamoxifen (Ellis et al, 2001). Both anastrozole and exemestane have also been shown to be more effective than tamoxifen in the preoperative setting (Dixon et al, 1999a, b; Geisler et al, 1999; Miller and Dixon, 2002).

In the adjuvant setting, while tamoxifen is the current standard of care, four large randomised controlled studies have favourably evaluated aromatase inhibitors against tamoxifen either 'head to head' or in sequence with adjuvant tamoxifen (ATAC, 2002; Goss et al, 2003; Buzdar, 2004; Coombes et al, 2004; Jakesz et al, 2004). Interestingly, an analysis of the ATAC data shows that ER + ve, PR -ve patients may particularly benefit from an aromatase inhibitor (ATAC, 2002; Buzdar, 2004).

\section{SAFETY ISSUES}

Data from postmenopausal women with advanced disease suggest that steroidal and non-steroidal aromatase inhibitors have similar tolerability profiles. In the ATAC study, patients receiving anastrozole had fewer vascular and uterine adverse events than those receiving tamoxifen (ATAC, 2002; Buzdar, 2004). Exemestane was associated with less severe flushing, sweating, nausea and oedema than tamoxifen (Paridaens et al, 2000; 2003). The most commonly reported adverse events in women treated with aromatase inhibitors were hot flushes, nausea, vomiting, headache and fatigue.

Emerging data suggest that there may be differences between the two types of aromatase inhibitor in their effects on end organs. The steroidal agent exemestane may have positive or neutral effects on lipid metabolism, as opposed to nonsteroidal agents which have shown unfavourable or neutral effects, and may have less impact 
on bone turnover than the nonsteroidals (Martinetti et al, 2003). Studies with exemestane have shown mixed effects on bone; exemestane has been seen to reverse the increased bone turnover induced by ovariectomy in an animal model (Goss et al, 2001), and in a comparison with letrozole, exemestane reduced bone resorption markers (Goss et al, 2002). However, other studies have also shown increased levels of bone turnover markers with exemestane (Martinetti et al, 2003; Geisler et al, 2004). In the adjuvant setting, increased osteoporosis has been demonstrated in trials with all the third-generation aromatase inhibitors (ATAC, IES, ARNO, MA17). Any differences between the aromatase inhibitors will become evident with long-term use (eg in adjuvant or prevention settings). Clinical trials are currently under way to investigate these effects. The consequences of the aromatase inhibitors on bone and lipids are explored further later in the supplement.

\section{FUTURE ROLE FOR AROMATASE INHIBITORS}

\section{Advanced disease}

Anastrozole and letrozole are already licensed for first-line therapy in advanced disease. Evidence suggests that in future exemestane may also be approved for first-line use. Results from a phase II, randomised, EORTC study comparing exemestane with tamoxifen treatment in patients who had previously received no hormonal therapy for metastatic disease revealed a better overall response rate for exemestane than tamoxifen (41 vs 17\%) (Paridaens et al, 2003). There was a lower incidence of severe flushing, sweating, nausea and oedema in women who received exemestane than tamoxifen. This study was extended into a phase III trial comparing time-to-disease progression of the two agents, and results for 382 patients were presented at the 2004 ASCO meeting. Median progression-free survival was found to be significantly longer with exemestane than tamoxifen (10.9 vs 6.7 months, $P=0.04$ ) and safety/tolerability assessments were also favourable for the aromatase inhibitor (Paridaens et al, 2004).

\section{Neoadjuvant therapy}

Currently, letrozole is the only aromatase inhibitor licensed for use as neoadjuvant therapy, based on the results of the P024 trial (Ellis et al, 2001), where more women with oestrogen receptor-positive $(\mathrm{ER}+\mathrm{ve})$ primary breast cancer who received letrozole went on to receive breast conserving surgery $(60 \%$ responded and $48 \%$ underwent successful breast-conserving surgery) compared with tamoxifen (41\% responded and 36\% underwent breast conservation). Several other studies have suggested that aromatase inhibitors may be more effective than tamoxifen in reducing tumour size prior to surgery (Dixon et al, 1999a, b; Geisler et al, 1999; Miller and Dixon, 2002).

\section{Adjuvant therapy}

Tamoxifen is the most widely used endocrine agent for adjuvant therapy, but it has drawbacks, in particular an increased risk of thromboembolic events and endometrial changes, including endometrial cancer (EBCTCG, 1998; Baum, 1999). Adjuvant trials of all third generation aromatase inhibitors show superior efficacy and equivalent or better tolerability. However, there are several difficulties in assessing the role of adjuvant endocrine therapy. Endocrine therapy is often administered in consort with chemotherapy making it difficult to separate the endocrine effects of the two types of treatment. Further head-to-head and sequencing trials are currently running that should add to our knowledge regarding use of the aromatase inhibitors in these settings. As these trials report, it is hoped that a consensus will emerge regarding whether aromatase inhibitors may replace tamoxifen in the adjuvant setting or whether sequencing with tamoxifen is more appropriate. Trials include:

TEAM: comparing adjuvant exemestane $v s$ adjuvant tamoxifen for 5 years in 4400 postmenopausal women with early breast cancer. This is a phase III randomised trial.

BIGFEMTA: comparing 5 years of tamoxifen, 5 years of letrozole, or sequenced therapy of 2-3 years each starting with either tamoxifen or letrozole. The trial recruited a total of 8028 patients between 1998 and 2003. Primary Core Analysis results presented at St Gallen 2005 show that letrozole significantly increased DFS $v s$ tamoxifen $(P=0.003)$ at a median follow-up of 35.5 months (Thürlimann, 2005).

ARNO: comparing 3 years' treatment of anastrozole with 3 years of tamoxifen, following 2 years' treatment with tamoxifen. The trial began in 1996, with initial data recently being reported in combination with results from the ABCSG Trial (total $n=3123$; Jakesz et al, 2004). After a median follow-up of 26 months, the hazard ratio for recurrence-free survival was 0.59 for anastrozole $v s$ tamoxifen $(95 \% \mathrm{CI}=0.42-0.82 ; P<0.0018)$, and 0.61 for distant recurrence-free survival (95\% CI $0.42-0.87 ; P=0.0067)$.

ICCG: comparing 2 years' treatment of exemestane with 2 years of tamoxifen, following 3 years' treatment with tamoxifen.

\section{Unresolved issues}

Evidence from the ATAC trial suggests that combining tamoxifen with anastrozole does not give additional benefit with results equivalent to tamoxifen alone and worse than anastrozole alone. The likely explanation for this is that in the low oestrogen environment created by an aromatase inhibitor, tamoxifen is more likely to display some agonist activity. Further, there is evidence in the advanced setting that use of a steroidal aromatase inhibitor after a nonsteroidal agent or vice versa can prolong clinical benefit (Lønning et al, 2000; Bertelli et al, 2002). Therefore, more work is needed to determine the optimal sequence of tamoxifen, steroidal and nonsteroidal aromatase inhibitors.

\section{Disease prevention}

Significant reduction in the emergence of contralateral breast cancer in all current adjuvant studies of third generation aromatase inhibitors raises the question of whether they might have a role in disease prevention, particularly bearing in mind their favourable safety/tolerability profile, an especially important consideration in this setting. Oestrogen has been implicated in the development of breast cancer, and oestrogen metabolites may also be directly carcinogenic; therefore, reduction in oestrogen levels in high-risk women with high levels of oestrogen may be beneficial. Among ongoing prevention trials are:

IBIS II: aims to determine the effectiveness of anastrozole $v s$ placebo in preventing breast cancer in healthy postmenopausal women at risk, and comparison between tamoxifen and anastrozole in postmenopausal women with ductal carcinoma in situ in 10000 women.

ApreS: compares exemestane with placebo in prevention of breast cancer in 666 women with the BRACA 1/2 mutation (Bevilacqua et al, 2001).

\section{Premenopausal women}

Another possible role for aromatase inhibitors may be following ovarian ablation/suppression in premenopausal women. Three important, linked trials are investigating this:

SOFT: examining tamoxifen alone vs tamoxifen plus ovarian function suppression $v s$ exemestane plus ovarian function suppression in 3000 patients.

TEXT: investigating the use of tamoxifen plus a gonadotropin-releasing hormone $(\mathrm{GnRH})$ analogue with or without 
chemotherapy $v s$ exemestane plus a GnRH analogue with or without chemotherapy in 1845 patients.

PERCHE: randomising patients from the TEXT trial into PERCHE if the investigator and/or patient are uncertain about the role of chemotherapy added to the complete oestrogen blockade - the choice of whether or not to use chemotherapy can be determined by randomisation in the PERCHE trial. Patients can be enrolled in both trials - first PERCHE (to determine whether or not chemotherapy is used) and then TEXT (to determine choice of tamoxifen or exemestane). PERCHE aims to enroll 1750 patients.

\section{Combination with cyclooxygenase 2 (COX2) inhibitors}

Following observations of cyclooxygenase 2 (COX2) involvement in breast carcinogenesis, the therapeutic potential of combining aromatase inhibitors with $\mathrm{COX} 2$ inhibitors is currently being investigated. Studies have suggested that this might bring improved response (Pesenti et al, 2001; Canney, 2003; Dirix et al, 2003). Early results of a feasibility study of exemestane plus the specific COX2 inhibitor celecoxib in postmenopausal women with histologically proven advanced or metastatic breast cancer showed $31 \%$ with a partial response and $42 \%$ having stable disease

\section{REFERENCES}

ATAC (Arimidex, Tamoxifen Alone or in Combination) Trialists' Group (2002) Anastrozole alone or in combination with tamoxifen versus tamoxifen alone for adjuvant treatment of postmenopausal women with early breast cancer: first results of the ATAC randomised trial. Lancet 359: $2131-2139$

Baum M (1999) Use of aromatase inhibitors in the adjuvant treatment of breast cancer. Endocr Relat Cancer 6: 231 - 234

Beatson GT (1896) On the treatment of inoperable cases of carcinoma of the mamma: suggestions for a new method of treatment, with illustrative cases. Lancet ii: $104-107,162-165$

Bertelli G, Garrone O, Merlano M (2002) Sequential use of aromatase inactivators and inhibitors in advanced breast cancer. Proc Am Soc Clin Oncol 21: 60a (Abstract 238)

Bevilacqua G, Silingardi V, Marchetti P (2001) Exemestane for the prevention of breast cancer in postmenopausal unaffected carriers of BRACA 1/2 mutations: aromasin prevention study (ApreS). Breast Cancer Res Treat 69: 226 (Abstract 139)

Blamey RW (2002) Guidelines on endocrine therapy of breast cancer. Eur J Cancer 38: 615-634

Bonneterre J, Thurlimann B, Robertson JF, Krzakowski M, Mauriac L, Koralewski P, Vergote I, Webster A, Steinberg M, von Euler M (2000) Anastrozole versus tamoxifen as first-line therapy for advanced breast cancer in 668 postmenopausal women: results of the Tamoxifen or Arimidex Randomized Group Efficacy and Tolerability study. J Clin Oncol 18: $3748-3757$

Breast Cancer Disease Site Group. Eisen A, Pritchard K, Johnston M, Oliver $\mathrm{T}$ (2002) The Role of Aromatase Inhibitors in the Treatment of Postmenopausal Women with Metastatic Breast Cancer 2002 September, p. 18. Toronto (ON): Cancer Care Ontario (CCO) (Practice Guideline Report; No. 1-5)

Buzdar A, Jonat W, Howell A, Jones SE, Blomqvist C, Vogel CL, Eiermann W, Wolter JM, Azab M, Webster A, Plourde PV (1996) Anastrozole, a potent and selective aromatase inhibitor versus megestrol acetate in postmenopausal women with advanced breast cancer: results of overview analysis of two Phase III trials. J Clin Oncol 14: $2000-2011$

Buzdar A, Jones S, Vogel C, Wolter JA (1997) A phase III trial comparing anastrozole ( 1 and 10 milligrams), a potent and selective aromatase inhibitor, with megestrol acetate in postmenopausal women with advanced breast cancer. Cancer 79: $730-739$

Buzdar AU (2004) Data from the arimidex, tamoxifen, alone or in combination (ATAC) trial: implications for use of aromatase inhibitors in 2003. Clin Cancer Res 10: $355 \mathrm{~S}-361 \mathrm{~S}$ following treatment with both agents (Canney, 2003). Now the following clinical trials are underway:

- NCIC CTG MA 27 is a randomised $2 \times 2$ trial comparing exemestane and anastrozole with or without celecoxib in 6800 women.

- The International Cooperative Breast Cancer Group/Breast International Group (ICCG/BIG) trial is a phase III study looking at sequential exemestane and tamoxifen with celecoxib $v s$ placebo.

Professor Bundred gives further consideration to this potential combination later in this supplement.

\section{CONCLUSIONS}

Aromatase inhibitors are rapidly proving to be a valuable addition to breast cancer therapy in postmenopausal women with oestrogen receptor positive tumours. As results of ongoing clinical trials become available, it is likely that these agents will be used earlier in the course of the disease and in the prevention setting, and may be used sequentially to prolong hormonal therapy and delay the need for chemotherapy, and possibly become part of a combination approach with other agents such as the COX2 inhibitors.
Canney PA (2003) A phase II study of the efficacy and tolerability of the combination of exemestane with the cyclooxygenase-2 inhibitor celecoxib in postmenopausal patients with advanced breast cancer. Proc Am Soc Clin Oncol 22: 40 (Abstract 158)

Coombes RC, Hall E, Gibson LJ, Paridaens R, Jassem J, Delozier T, Jones SE, Alvarez I, Bertelli G, Ortmann O, Coates AS, Bajetta E, Dodwell D, Coleman RE, Fallowfield LJ, Mickiewicz E, Andersen J, Lonning PE, Cocconi G, Stewart A, Stuart N, Snowdon CF, Carpentieri M, Massimini G, Bliss JM, Intergroup Exemestane Study (2004) A randomized trial of exemestane after two to three years of tamoxifen therapy in postmenopausal women with primary breast cancer. $N$ Engl J Med 350: $1081-1092$

Dirix L, Piccart MJ, Lohrisch C, Beex L, Nooij M, Cameron D, Biganzoli L, Cufer T, Yague C, Duchateau L, Lobelle J, Paridaens R (2001) Efficacy of and tolerance to exemestane (E) versus tamoxifen (T) in 1st line hormone therapy (HT) of postmenopausal metastatic breast cancer (MBC) patients (pts): a European Organisation for the Research and Treatment of Cancer (EORTC Breast Group) phase II trial with Pharmacia Upjohn. Proc Am Soc Clin Oncol 20: 29a (Abstract 114)

Dirix LY, Ignacio J, Nag S (2003) Final results from an open-label, multicenter, controlled study of exemestane $+/-$ celecoxib in postmenopausal women with advanced breast cancer $(\mathrm{ABC})$ progressed on tamoxifen (T). Proc Am Soc Clin Oncol 22: 20 (Abstract 77)

Dixon JM, Love CD, Renshaw L, Bellamy C, Cameron DA, Miller WR, Leonard RC (1999a) Lessons from the use of aromatase inhibitors in the neoadjuvant setting. Endocr Relat Cancer 6: 227-230

Dixon MJ, Renshaw C, Bellamy DA, Cameron DA, Miller WR (1999b) 'Arimidex' as neoadjuvant therapy causes large reductions in tumor volume in postmenopausal women with large operable breast cancers. Proc Am Soc Clin Oncol 18: 92a

Dombernowsky P, Smith I, Falkson G, Leonard R, Panasci L, Bellmunt J, Bezwoda W, Gardin G, Gudgeon A, Morgan M, Fornasiero A, Hoffmann W, Michel J, Hatschek T, Tjabbes T, Chaudri HA, Hornberger U, Trunet PF (1998) Letrozole, a new oral aromatase inhibitor for advanced breast cancer: double-blind randomized trial showing a dose effect and improved efficacy and tolerability compared with megestrol acetate. J Clin Oncol 16: 453-461

Early Breast Cancer Trialists Collaborative Group (1998) Tamoxifen for early breast cancer: an overview of the randomised trials. Lancet 351: $1451-1467$

Eiermann W, Paepke S, Appfelstaedt J, Llombart-Cussac A, Eremin J, Vinholes J, Mauriac L, Ellis M, Lassus M, Chaudri-Ross HA, Dugan M, Borgs M, Letrozole Neo-Adjuvant Breast Cancer Study Group (2001) 
Preoperative treatment of postmenopausal breast cancer patients with letrozole: a randomized double-blind multicenter study. Ann Oncol 12: $1527-1532$

Ellis MJ, Coop A, Singh B, Mauriac L, Llombert-Cussac A, Janicke F, Miller WR, Evans DB, Dugan M, Brady C, Quebe-Fehling E, Borgs M (2001) Letrozole is more effective neoadjuvant endocrine therapy than tamoxifen for ErbB-1- and/or ErbB-2-positive, estrogen receptor-positive primary breast cancer: evidence from a phase III randomized trial. J Clin Oncol 19: $3808-3816$

Geisler J, Berntsen L, Ottestad L, Lindtjoern B, Dowsett M, Lønning PE (1999) Comparison of the effects of neoadjuvant 'Arimidex' (anastrozole) on plasma and intratumor tissue estrogen levels in postmenopausal breast cancer patients. Breast 8: 241

Geisler J, Lonning PE, Krag LE, Ottestad L, Bremnes Y, Hagen AI, Schlichting E, Ofjord ES, Polli A, Massimini G (2004) Estrogens and bone metabolism in postmenopausal women with early breast cancer at low risk treated with exemestane: a randomized placebo-controlled study. J Clin Oncol, ASCO Proc 22(Suppl): (Abstract 531)

Goss PE, Grynpas MD, Josse R (2001) The effects of the steroidal aromatase inactivator exemestane on bone and lipid metabolism in the ovariectomized rat. Breast Cancer Res Treat 69: 224 (Abstract 132)

Goss PE, Ingle JN, Martino S, Robert NJ, Muss HB, Piccart MJ, Castiglione M, Tu D, Shepherd LE, Pritchard KI, Livingston RB, Davidson NE, Norton L, Perez EA, Abrams JS, Therasse P, Palmer MJ, Pater JL (2003) A randomized trial of letrozole in postmenopausal women after five years of tamoxifen therapy for early-stage breast cancer. $N$ Engl J Med 349: $1793-1802$

Goss PE, Winer EP, Tannock IF, Schwartz LH (1999) Randomized phase III trial comparing the new potent and selective third-generation aromatase inhibitor vorozole with megestrol acetate in postmenopausal advanced breast cancer patients: The North American Vorozole Study Group. J Clin Oncol 17: 52-63

Goss P, Thompsen T, Banke-Bochita J (2002) A randomized, placebocontrolled, explorative study to investigate the effect of low estrogen plasma levels on markers of bone turnover in healthy postmenopausal women during the 12-week treatment with exemestane or letrozole. Breast Cancer Res Treatment 76(Suppl 1): S76 (Abstract 267, Updated January 2003)

Gruber CJ, Tschuffuel W, Schneeberger C, Huber JC (2002) Production and actions of estrogens. $N$ Engl J Med 346: $340-352$

Howell A, Robertson JF, Vergote I (2003) A review of the efficacy of anastrozole in postmenopausal women with advanced breast cancer with visceral metastases. Breast Cancer Res Treat 82: 215-222

Ingle JN, Johnson PA, Suman VJ, Gerstner JB, Mailliard JA, Camoriano JK, Gesme Jr DH, Loprinzi CL, Hatfield AK, Hartmann LC (1997) A randomised phase II trial of two dosage levels of letrozole as third-line hormonal therapy for women with metastatic breast carcinoma. Cancer 80: $218-224$

Jakesz R, Kaufmann M, Gnant M, Jonat W, Mittlboeck M, Greil R, Tausch C, Hilfrich J, Kwasny W, Samonigg H, on behalf of the ABCSG, the GABG (2004) Benefits of switching postmenopausal women with hormonesensitive early breast cancer to anastrozole after 2 years adjuvant tamoxifen: combined results from 3,123 women enrolled in the ABCSG Trial 8 and the ARNO 95 Trial. 27th Annual San Antonio Breast Cancer Symposiumm, December 8-11, 2004, San Antonio, Texas (Abstract 2)

Jones S, Vogel C, Arkhipov A, Fehrenbacher L, Eisenberg P, Cooper B, Honig S, Polli A, Whaley F, di Salle E, Tiffany J, Consonni A, Miller L (1999) Multicenter, phase II trial of exemestane as third-line hormonal therapy of postmenopausal women with metastatic breast cancer. J Clin Oncol 17: $3418-3425$

Kaufmann M, Bajetta E, Dirix LY, Fein LE, Jones SE, Zilembo N, Dugardyn JL, Nasurdi C, Mennel RG, Cervek J, Fowst C, Polli A, di Salle E, Arkhipov A, Piscitelli G, Miller LL, Massimini G (2000) Exemestane is superior to megestrol acetate after tamoxifen failure in postmenopausal women with advanced breast cancer: result of a phase III randomised double-blind trial. J Clin Oncol 18: 1399-1411

Lønning PE, Bajetta E, Murray R, Tubiana-Hulin M, Eisenberg PD, Mickiewicz E, Celio L, Pitt P, Mita M, Aaronson NK, Fowst C, Arkhipov A, di Salle E, Polli A, Massimini G (2000) Activity of exemestane (Aromasin ${ }^{\circledR}$ ) in metastatic breast cancer after failure of nonsteroidal aromatase inhibitors: a phase II trial. J Clin Oncol 18: $2234-2244$

Martinetti A, Zilembo N, Ferrari L (2003) Bone turnover markers and insulin-like growth factor components in metastatic breast cancer: results from a randomised trial of exemestane $v s$ megestrol acetate. Anticancer Res 23: $3485-3492$

Milla-Santos A, Milla L, Rallo L, Solana V (2000) Anastrozole vs tamoxifen in hormonodependent advanced breast cancer: a phase II randomized trial. Breast Cancer Res Treat 64 (Abstract 173)

Miller WR (1991) Aromatase activity in breast tissue. J Steroid Biochem Mol Biol 39: $783-790$

Miller WR, Dixon JM (2001) Local endocrine effects of aromatase inhibitors within the breast. J Steroid Biochem Mol Biol 79: 93-102

Miller WR, Dixon JM (2002) Endocrine and clinical endpoints of exemestane as neoadjuvant therapy. Cancer Control 9(Suppl): 9-15

Mouridsen H, Gershanovich M, Sun Y, Perez-Carrion R, Boni C, Monnier A, Apffelstaedt J, Smith R, Sleeboom HP, Janicke F, Pluzanska A, Dank M, Becquart D, Bapsy PP, Salminen E, Snyder R, Lassus M, Verbeek JA, Staffler B, Chaudri-Ross HA, Dugan M (2001) Superior efficacy of letrozole versus tamoxifen as first-line therapy for postmenopausal women with advanced breast cancer: results of a phase III study of the International Letrozole Breast Cancer Group. J Clin Oncol 19: 2596- 2606

Nabholtz JM, Buzdar A, Pollak M, Harwin W, Burton G, Mangalik A, Steinberg M, Webster A, von Euler M (2000) Anastrozole is superior to tamoxifen as first-line therapy for advanced breast carcinoma in postmenopausal women: results of a North American multicenter randomized trial. J Clin Oncol 18: $3758-3767$

National Comprehensive Cancer Network (2005) Breast cancer. Clinical practice guidelines in oncology - v.1.200. Available at: http:// www.nccn.org/physician_gls/f_guidelines.html last accessed March 2005

O’Neill JS, Elton RA, Miller WR (1988) Aromatase activity in adipose tissue from breast quadrants: a link with tumour site. Br Med J (Clin Res Edn) 296: $741-743$

Paridaens R, Dirix L, Beex L, Nooij M, Cufer T, Lohrisch C, Biganzoli L, Van Hoorebeeck I, Duchateau L, Lobelle J-P, Piccart M (2000) Exemestane (Aromasin) is active and well tolerated as first-line hormonal therapy (HT) of metastatic breast cancer (MBC) patients (pts): results of a randomized Phase II trial. Proc Am Soc Clin Oncol 19(36 Meet): 83a (Abstract 316)

Paridaens R, Dirix L, Lohrisch C, Beex L, Nooij M, Cameron D, Biganzoli L, Cufer T, Duchateau L, Hamilton A, Lobelle JP, Piccart M, European Organization for the Research and Treatment of Cancer (EORTC)Investigational Drug Branch for Breast Cancer (IDBBC) (2003) Mature results of a randomized phase II multicenter study of exemestane versus tamoxifen as first-line hormone therapy for postmenopausal women with metastatic breast cancer. Ann Oncol 14: $1391-1398$

Paridaens R, Therasse P, Dirix L, Beex L, Piccart M, Cameron D, Cufer T, Roozendaal K, Nooij M, Mattiacci MR (2004) First line hormonal treatment (HT) for metastatic breast cancer (MBC) with exemestane (E) or tamoxifen $(\mathrm{T})$ in postmenopausal patients (pts) - a randomized phase III trial of the EORTC Breast Group. J Clin Oncol, ASCO Proc 22(Suppl): (Abstract 515)

Pesenti E, Masferrer JL, di Salle E (2001) Effect of exemestane and celecoxib alone or in combination on DMBA-induced mammary carcinoma in rats. Breast Cancer Res 69: 288 (Abstract 445)

Simpson ER, Davis SR (2001) Minireview: aromatase and the regulation of estrogen biosynthesis - some new perspectives. Endocrinology 142: $4589-4594$

Smith IE, Dowsett M (2003) Aromatase inhibitors in breast cancer. N Engl J Med 348: $2431-2442$

Thürlimann B, BIG 1-98 Collaborative Group (2005) BIG 1-98: a prospective randomized double-blind double-dummy phase III study to evaluate letrozole as adjuvant endocrine therapy for postmenopausal women with receptor-positive breast cancer. Breast 14(Suppl 1): S3 (Abstract S4)

Winer EP, Hudis C, Burstein HJ, Chlebowski RT, Ingle JN, Edge SB, Mamounas EP, Gralow J, Goldstein LJ, Pritchard KI, Braun S, Cobleigh MA, Langer AS, Perotti J, Powles TJ, Whelan TJ, Browman GP (2002) American Society of Clinical Oncology Technology Assessment on the use of aromatase inhibitors as adjuvant therapy for women with hormone receptor-positive breast cancer: status report 2002. J Clin Oncol 20: $3317-3327$

Winer EP, Hudis C, Burstein HJ, Bryant J, Chlebowski RT, Ingle JN, Edge SB, Mamounas EP, Gelber R, Gralow J, Goldstein LJ, Pritchard KI, Braun S, Cobleigh MA, Langer AS, Perotti J, Powles TJ, Whelan TJ, Browman GP (2003) American Society of Clinical Oncology Technology Assessment Working Group update: use of aromatase inhibitors in the adjuvant setting. J Clin Oncol 21: 2597-2599 